\title{
Synthetic cathinone abuse
}

This article was published in the following Dove Press journal:

Clinical Pharmacology:Advances and Applications

I July 2013

Number of times this article has been viewed

\section{Michael Capriola}

Thomasville Medical Center, Thomasville, NC, USA
Correspondence: Mike Capriola

Thomasville Medical Center, 207 Old

Lexington Road,Thomasville,

NC 27360, USA

Tel + I 336-472-2000

Email mikecapriola@gmail.com
Abstract: The abuse of synthetic cathinones, widely known as bath salts, has been increasing since the mid-2000s. These substances are derivatives of the naturally occurring compound cathinone, which is the primary psychoactive component of khat. The toxicity of synthetic cathinones includes significant sympathomimetic effects, as well as psychosis, agitation, aggression, and sometimes violent and bizarre behavior. Mephedrone and methylenedioxypyrovalerone are currently the predominantly abused synthetic cathinones.

Keywords: designer drugs/chemistry, street drugs/pharmacology, substance-related disorders/ epidemiology, alkaloids/poisoning

\section{Introduction}

A recent manifestation of the interaction between substance abusers, those seeking to profit by providing substances of abuse, and the desire of both parties to avoid legal censure, is the emergence of bath-salt abuse. Bath salts in this context refer to several synthetic cathinones sold as either bath salts or plant food, but not intended for any horticultural or personal hygiene use. Despite the ubiquitous packaging disclaimer "not intended for human consumption," these substances are sold as "legal highs" and drugs of abuse. ${ }^{1}$

\section{History}

Cathinone is a naturally occurring phenylalkylamine which is found in the leaves of khat (Catha edulis), a shrub or small tree indigenous to East Africa and the Arabian Peninsula. ${ }^{2}$ Historical references to the chewing of khat leaves for their euphoric and stimulant effects dates back many centuries, and today this practice is prevalent in such countries as Somalia, Yemen, Kenya, and Ethiopia. ${ }^{3}$ Khat leaves contain multiple compounds, notably phenylalkylamine alkaloids that include norpseudoephedrine, cathinone, and cathine. ${ }^{4}$ Studies in the 1930 s to determine the psychoactive components of khat initially erroneously identified norpseudoephedrine as the main psychoactive compound. ${ }^{4}$ In 1975, cathinone was isolated from khat leaves and determined to be its principal psychoactive component. ${ }^{5}$ Although cathinone is a chiral molecule, khat leaves contain only the $S(-)$ enantiomer, ${ }^{6}$ and synthesis of the racemate was not achieved until $1982 .{ }^{7}$ Cathinone begins to decompose shortly after leaves are harvested, and thus fresh leaves are sought for chewing. This may explain why khat chewing has largely remained limited to geographic regions where Catha edulis grows. ${ }^{3}$ In distinction to synthetic cathinone abuse, habitual khat chewing reportedly results 
in only mild psychological dependence and mild withdrawal symptoms. ${ }^{8,9}$

As reviewed by Kelly, the earliest report of synthetic cathinone synthesis is in 1928 with the synthesis of methcathinone in Germany, followed by the synthesis of mephedrone in $1929 .{ }^{10}$ Today, there are approximately 30 known synthetic cathinones. ${ }^{10}$

Although many synthetic cathinones have been investigated as anorectics, central nervous system stimulants, and antidepressants, clinical utility has been hindered by problems with abuse and dependence. For instance, methcathinone was initially used as an antidepressant in the USSR but removed from clinical use due to abuse. ${ }^{11}$ Currently, the synthetic cathinone diethylpropion is available for use as an anorectic, but is infrequently prescribed due to abuse and dependence. In addition, diethylpropion has been shown to be neurotoxic in animal studies. ${ }^{12}$ Pyrovalerone has been used in the past for chronic fatigue, ${ }^{13}$ while the most clinically successful cathinone is bupropion, which is widely prescribed for depression and smoking cessation. ${ }^{14}$

\section{Patterns of abuse}

Large-scale abuse of synthetic cathinones began with the use of methcathinone in the USSR in the 1970s and 1980s. ${ }^{11}$ Clandestine methcathinone manufacture first appeared in the US in Michigan in 1991, followed by significant problems of abuse in the early 1990s. ${ }^{11}$

Since 2004, abuse of various synthetic cathinones has been reported in Asia, Israel, the EU, and the US, possibly fueled by a decrease in purity and availability of other stimulant drugs of abuse, including MDMA (3,4-methylenedioxy- $N$-methylamphetamine) and cocaine. ${ }^{15}$ Data regarding synthetic cathinones seized in the EU since 2006 reveals ten different substances, including mephedrone, methylone, and MDPV (3,4-methylenedioxypyrovalerone), with mephedrone involved in $89 \%$ of seizures in the UK. ${ }^{14}$ US Customs and Border Protection drug-seizure data report the seizure of multiple different synthetic cathinones between July 2009 and April 2011, including MDPV and mephedrone. ${ }^{1}$ User surveys, poison center reports, and case series in the US and Europe indicate that current synthetic cathinone abuse involves primarily mephedrone and MDPV, with methylone, naphyrone, and flephedrone being less often implicated..$^{9,16-19}$

Law-enforcement data indicate that synthetic cathinone supply frequently originates in the People's Republic of China, Pakistan, and India. ${ }^{1}$ Substances are then sold to the public via the Internet and in retail establishments, includ- ing "head shops," gas stations, convenience stores, and skateboard shops. Products are labeled as bath salts, plant food/fertilizer, vacuum freshener, pond cleaner, and insect repellent, and are typically sold as tablets or white powders. ${ }^{1}$ While oral ingestion and nasal insufflation have been reported as the most common means of use, ${ }^{9,16}$ parenteral exposure has also been described, with a recent case series reporting injection as the most common means of use. ${ }^{18}$

There is little epidemiologic data regarding synthetic cathinone use. Survey data imply that at least among certain demographic groups, use may be widespread. In a 2010 online survey sponsored by a magazine popular with UK clubbers, $41.7 \%$ of 2200 respondents reported having used mephedrone. ${ }^{15,20}$ A 2010 survey of 1006 high school and university students in Scotland reported a $20.3 \%$ prevalence of mephedrone use. ${ }^{9}$ Evidence from poison center calls and drug seizures in the US support the concept that synthetic cathinone abuse is a recent and increasing phenomenon. Synthetic cathinone-related calls to US poison centers increased from zero in 2009 to 304 in 2010 and 6138 in 2011. ${ }^{16,21}$ Drug samples seized in the US and analyzed by state and local forensic laboratories reveal 34 reports of synthetic cathinones in 2009 and 628 in 2010. 17,22

Coingestion of other drugs of abuse and alcohol frequently accompanies synthetic cathinone use. ${ }^{19,23,24}$ While there are no data regarding people seeking treatment for synthetic cathinone dependence/addiction, users have reported a strong compulsion to redose, as well as addiction/dependence. ${ }^{9}$

The legal status of cathinone analogues continues to evolve as new substances are produced in order to evade existing laws. ${ }^{1}$ Mephedrone and several other substituted cathinones were banned in the EU in $2010,{ }^{23}$ and as of July 2012, mephedrone, MDPV, and methylone have been added to Schedule I of the Controlled Substances Act in the US. ${ }^{25}$

\section{Chemistry}

As seen in Figure 1, cathinones are structurally related to amphetamines. ${ }^{26}$ Both are substituted phenethylamines

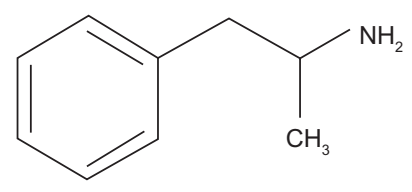

Amphetamine

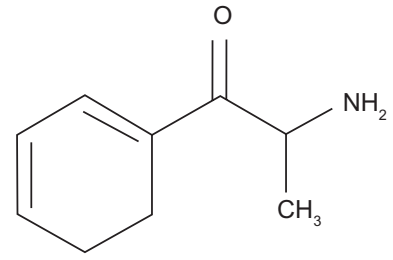

Cathinone
Figure I Amphetamine and cathinone structures. 
with cathinones possessing a ketone group at the $\beta$-carbon position. Figure 2 demonstrates the general structure of substituted cathinones. Various R-group substitutions give rise to the approximately 30 known cathinones, many of which have amphetamine analogues to which they are identical, save for the $\beta$-carbon ketone group. ${ }^{26}$ Thus, replacing a hydrogen with a ketone converts amphetamine to cathinone, methamphetamine to methcathinone, and MDMA to methylone. ${ }^{10}$ The structure of several cathinones recently implicated in recreational abuse can be seen in Figure 3.

\section{Pharmacokinetics}

At present, there is a scarcity of data concerning the pharmacokinetics of synthetic cathinones in humans. However, insights can be gleaned from animal data as well as inferred from studies of naturally occurring cathinones.

The pharmacokinetics of cathinone have been studied in humans by multiple investigators since the initial isolation of this compound from khat leaves in 1975. ${ }^{4}$ After chewing khat leaves, absorption takes place primarily in the oral mucosa, with a secondary contribution from absorption in the stomach and small intestine. ${ }^{27}$ Extraction of khat alkaloids by mastication has been reported to be very efficient; ${ }^{27}$ however, chewing results in delayed peak plasma concentrations when compared to administering oral cathinone. Following chewing khat leaves, time to peak plasma concentrations of $138 \pm 39$ minute $^{27}$ and $127 \pm 30$ minute $^{28}$ have been reported, while administration of gelatin cathinone capsules produced peak plasma concentrations in 72 minutes. ${ }^{29}$ Orally ingested cathinone undergoes extensive first-pass hepatic metabolism primarily to norpseudoephedrine with a smaller fraction converted to norephedrine..$^{2,27,29,30}$ Very little cathinone is excreted unchanged, with studies in humans reporting urinary excretion of unchanged cathinone to be between $2 \%^{2}$ and $7 \%{ }^{31}$

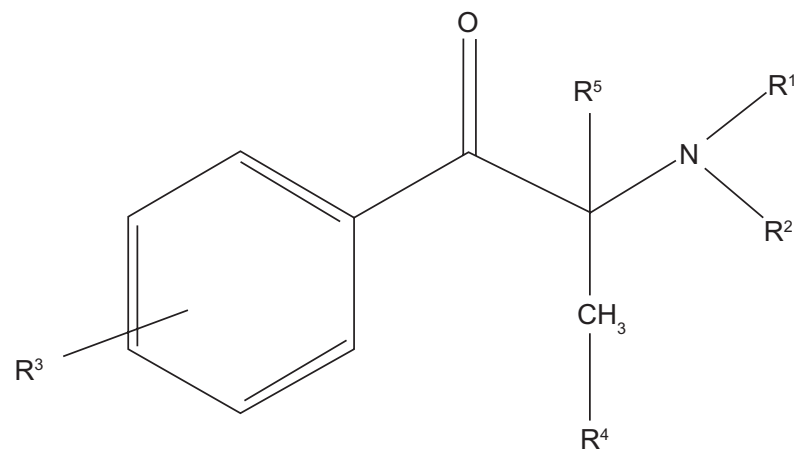

Figure 2 General cathinone derivative structure.<smiles>CNC(C)C(=O)c1ccc(C)cc1</smiles>

Mephedrone

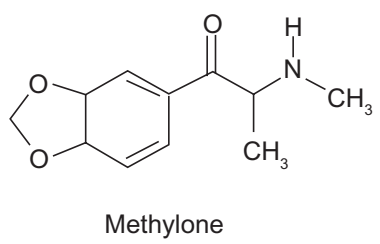

Figure 3 Selected substituted cathinone structures.

Abbreviation: MDPV, methylenedioxypyrovalerone.

The half-life of cathine is reported to be $5.2 \pm 3.4$ hours, and cathinone $1.5 \pm 0.8$ hours in humans. ${ }^{32}$

Research regarding synthetic cathinone pharmacokinetics in humans is lacking. There are no controlled studies of human in vivo synthetic cathinone pharmacokinetics; however, several studies examining urinary metabolites in people who claim to have ingested synthetic cathinones exist. ${ }^{33-36}$ In vivo animal studies have been published, ${ }^{33,35-37}$ as have in vitro investigations utilizing animal hepatocytes ${ }^{38,39}$ and human liver microsomes. ${ }^{36,37,40}$ Generalizing the findings of these studies is complicated not only by varying experimental models but also by the multiple different synthetic cathinones studied. However, within the framework of these limitations, several preliminary conclusions may be drawn. Similar to naturally occurring cathinone, synthetic cathinones appear to undergo extensive phase I and II metabolism, ${ }^{33-38,40}$ with little of the drug excreted unchanged in urine. ${ }^{35,37}$ Commonly identified phase I reactions are demethylation and oxidation, as well as reduction of the $\beta$-keto moiety. ${ }^{35,36,38}$ Glucuronidation of metabolites has been described by several investigators. ${ }^{37,38}$ Indirect evidence of sulfate conjugation has been reported; ${ }^{33}$ however, other investigations have been unable to confirm this. ${ }^{37,38}$ Human liver microsomes have been used by Meyer et al in two separate studies, with the finding that human cytochrome P450 (CYP) enzymes CYP2B6, CYP2C19, CYP2D6, and CYP1A2 are involved in synthetic cathinone metabolism. ${ }^{36,37}$ While there are no studies examining synthetic cathinone half-lives in humans, surveys of users suggest that the duration of effects of mephedrone and MDPV are "short," with users reporting frequent redosing at 1- to 2-hour intervals and a duration of effects of approximately $2-4$ hours. ${ }^{41,42}$ This is not 
inconsistent with findings in rat hepatocytes of a half-life of approximately 1 hour for mephedrone. ${ }^{38}$

Compared to amphetamines, the ketone group of cathinones confers a greater polarity and a predicted increased lipophilicity. ${ }^{43}$ Thus, diffusion across the blood-brain barrier may be decreased. ${ }^{43}$ However several pyrrolidine derivatives, including MDPV and MDPPP (3,4-methylenedioxy$\alpha$-pyrrolidinopropiophenone), have lower polarity and have shown high solubility in organic solvents. ${ }^{15}$ In addition, recent in vitro studies of mephedrone, MDPV, methylone, ethylone, butylone, and naphyrone demonstrated high blood-brain barrier permeability of all these synthetic cathinones. ${ }^{44}$

\section{Mechanism of action}

In vitro studies utilizing human and animal cell preparations suggest that cathinones acutely increase extracellular dopamine, norepinephrine, and serotonin levels. Similar to amphetamines, cathinones inhibit dopamine, norepinephrine, and serotonin plasma membrane and vesicular monoamine transporters, resulting in increased neurotransmitter synaptic concentration. ${ }^{45,46}$ Different cathinones display varying ability to cause increases in extracellular dopamine, norepinephrine, and serotonin levels, which may account for the different mood-altering effects, toxicity, and potential for addiction related to these compounds. Mephedrone, for instance, has been shown to significantly inhibit norepinephrine reuptake. ${ }^{46}$ While the expected sympathomimetic effects have not been specifically demonstrated in human studies, case reports do support a strong sympathomimetic effect of some synthetic cathinones, including mephedrone. ${ }^{18,24,47}$ The reported addictive potential of several synthetic cathinones is likely related to effects on increasing extracellular dopamine, as has been demonstrated in animal models. ${ }^{48}$

\section{Toxicology}

The current body of knowledge regarding the adverse effects of synthetic cathinones is based largely on case reports, data from poison centers, and surveys of users. Inherent flaws in these data are likely, as users may not be accurate regarding substances ingested, the amounts ingested, and the presence of coingestions. Compounding this is the limited ability to test accurately for synthetic cathinones, ${ }^{15}$ and purchased products that do not contain the substances advertised or contain unlisted compounds in addition to the advertised drug. Inaccurate labeling of products has been reported, with products containing synthetic cathinones other than the listed compound, other substances of abuse, including MDMA and ketamine, and pharmaceuticals, including acetaminophen, caffeine, benzocaine, and lidocaine ${ }^{49,50}$ Additionally, products sold as cocaine and MDMA have been found to contain synthetic cathinones. ${ }^{51,52}$ Finally, a review of 15 products sold as "legal highs" in the USA found no ingredients were listed on any of the packages, thus making it very difficult for patients to report exposures accurately. ${ }^{19}$

\section{Toxicity of naturally occurring cathinones}

The reported toxicity of the natural substances cathinone and cathine appears less severe than many of their synthetic counterparts. This may be due to chewing khat representing the primary means of ingestion and the bulk of leaves that must be chewed in order to produce significant toxic effects. ${ }^{29}$ Described toxic effects of chewing khat include depression, irritability, insomnia, anorexia, and paranoid psychosis. Adverse cardiovascular effects include hypertension, tachycardia, and an increased incidence of acute myocardial infarction and cerebral vascular accidents. ${ }^{53}$ Chewing khat is also associated with an increased incidence of oral cancer. ${ }^{54}$

\section{Toxicity of synthetic cathinones}

Toxic effects of synthetic cathinones include sympathomimetic effects, as well as psychological effects, including aggression, agitation, paranoia, and delusions. ${ }^{16,19,55}$ Seizures, hyponatremia, hyperthermia, rhabdomyolysis, disseminated intravascular coagulation, renal failure, and hepatic failure have also been reported, as have several deaths. . $^{19,47,56,57}$ Several reports, primarily from Eastern Europe, document parkinsonism in patients following long-term parenteral use of methcathinone. Manganese contamination of homemade methcathinone has been identified as the cause. ${ }^{58,59}$

Chronic amphetamine use is known to be neurotoxic to dopaminergic neurons, resulting in long-term reductions in brain dopamine concentrations in chronic users. ${ }^{60}$ Serotonergic neurotoxicity as a result of MDMA use occurs in animals, and possibly humans. ${ }^{61}$ Whether synthetic cathinone abuse is related to dopaminergic or serotonergic neurotoxicity in humans is unknown; however, serotonin neurotoxicity has been described with methylone and mephedrone in rats. ${ }^{62}$

\section{User-reported adverse effects}

User-reported adverse effects of synthetic cathinone use commonly include agitation, paranoia, bruxism, palpitations, headache, and depression. ${ }^{9,63,64}$ A 2010 survey of 1006 students in Scotland with 205 mephedrone users found $56 \%$ reported at least one adverse effect, most commonly bruxism $(28.3 \%)$ and paranoia $(24.9 \%){ }^{9}$ 
Table I Synthetic cathinone toxicity: case reports with $\geq 15$ patients without analytical confirmation of synthetic cathinone exposure

\begin{tabular}{|c|c|c|c|c|c|c|c|c|c|c|}
\hline \multirow[t]{2}{*}{ Study } & \multirow[t]{2}{*}{ Patients } & \multirow{2}{*}{$\begin{array}{l}\text { Reported } \\
\text { exposure }\end{array}$} & \multicolumn{8}{|c|}{ Percent reporting } \\
\hline & & & Agitation & Tachycardia & HTN & Seizure & $\begin{array}{l}\text { Chest } \\
\text { pain }\end{array}$ & Hyperpyrexia & $\begin{array}{l}\text { Elevated } \\
\text { CK }\end{array}$ & $\begin{array}{l}\text { Low } \\
\text { sodium }\end{array}$ \\
\hline $\mathrm{CDC}^{\prime}$ & 35 & $\begin{array}{l}\text { MDPV, } \\
\text { "bath salts" }\end{array}$ & 66 & 63 & 23 & 29 & $\mathrm{a}$ & $\mathrm{a}$ & 2.9 & $\mathrm{a}$ \\
\hline Dargan et $\mathrm{al}^{23}$ & 72 & Mephedrone & 38.9 & 36.1 & 13.9 & 6.9 & 12.5 & 0 & $13.8^{\mathrm{b}}$ & 1.4 \\
\hline Regan et $\mathrm{a}^{24}$ & 57 & Mephedrone & 40.4 & 79 & 74 & 3.5 & 24.6 & $d$ & $33.3^{c}$ & a \\
\hline Wood et al ${ }^{47}$ & 15 & Mephedrone & 53.3 & 40 & 20 & 20 & $b$ & $\mathrm{a}$ & $\mathrm{a}$ & $\mathrm{a}$ \\
\hline
\end{tabular}

Notes: a Not reported; ${ }^{\mathrm{b}} \mathrm{CK}$ measured in 18 patients, elevated in ten; ${ }^{\mathrm{C}} \mathrm{CK}$ measured in 20 patients, elevated in 19 ; dindividual data not given. Temperature range of all patients $34.8^{\circ} \mathrm{C}-38.8^{\circ} \mathrm{C}$.

Abbreviations: CK, creatine kinase; HTN, hypertension; MDPV, methylenedioxypyrovalerone; CDC, Centers for Disease Control and Prevention.

Mixmag is a publication popular with UK clubbers and host of the large Mixmag Drugs Survey, which in 2012 included online responses from over 15,500 respondents. Commonly reported adverse mephedrone effects included depression (41\%), agitation (23\%), "overheating" (26\%), severe headache (12\%), and chest pain $(10 \%) .{ }^{63}$ In a smaller study from Ireland utilizing privileged-access interviewing of eleven intravenous users of mephedrone, all users reported intense paranoia, and two reported extreme aggression and violence. ${ }^{64}$

\section{Adverse effects reported to poison centers}

Calls by physicians to the National Poisons Information Service in the UK from March 2009 to February 2010 included 188 calls regarding cathinones, with 131 of these concerning mephedrone. Reported adverse effects included agitation or aggression (24\%), tachycardia (22\%), confusion or psychosis (14\%), chest pain (13\%), and palpitations $(11 \%) .{ }^{16} \mathrm{~A}$ report documenting synthetic cathinone-related calls to Texas poison centers in 2010 and 2011 found 362 calls, with common adverse effects being tachycardia (45.9\%), agitation (39.2\%), hypertension (21.0\%), and hallucinations (17.7\%). ${ }^{55}$ During an 8-month period in 2010 and 2011, 236 calls were received by poison centers in Kentucky and Louisiana regarding synthetic cathinone intoxication. Commonly reported toxicities included agitation (82\%), combative behavior (57\%), tachycardia (56\%), hallucinations $(40 \%)$, and paranoia (36\%). This study also included descriptions of severe delusional behavior, including leaving a 2-year-old child in a highway "because she had demons," firing guns at nonexistent people and "demons," and destroying all the windows in a home and walking barefoot through the resulting broken glass. One patient died as a result of a self-inflicted gunshot wound while delusional. ${ }^{19}$

\section{Adverse effects reported in case series}

Multiple case reports from emergency departments concerning patients presenting with synthetic cathinone toxicity, without analytical confirmation of substances ingested, have been published. Findings are summarized in Table 1.

Case reports in which the presence of synthetic cathinones was confirmed by body-fluid or tissue analysis include multiple single-patient case reports, a series of three deaths involving methylone, and a series of seven patients with mephedrone toxicity. ${ }^{17,51,56,57,65-70} \mathrm{~A}$ series of 13 patients with confirmed MDPV intoxication has been published, but clinical findings in patients with confirmed and unconfirmed exposures are grouped together. ${ }^{19}$ In the report of seven patients with confirmed mephedrone ingestion, five of the patients had only synthetic cathinones detected on drug screening, while the other two patients also tested positive for cocaine. Adverse effects included heart rate $>100$ (five patients), systolic blood pressure $>160$ (three), agitation (four), and seizure (one). One patient had hyponatremia with a serum sodium concentration of $125 \mathrm{mmol} / \mathrm{L}$, and one patient had rhabdomyolysis. No patients had significant hyperpyrexia. ${ }^{65}$ In the three reported deaths from methylone intoxication, all patients had hyperpyrexia and seizures, with metabolic acidosis, disseminated intravascular coagulation, and acute renal failure also reported. ${ }^{66}$ Single-patient case reports have also reported hyperpyrexia, seizures, hyponatremia, rhabdomyolysis, and metabolic acidosis. ${ }^{51,56,57,69}$

\section{Conclusion}

The recreational use of synthetic cathinones, widely known as bath salts, has been the subject of much recent interest. Synthetic cathinones are derivatives of the naturally occurring compound cathinone, which is the primary psychoactive component of khat. Cathinones are structurally related to amphetamines, and their mechanisms of action are thought 
to be similar. Although the first synthetic cathinones were synthesized in the 1920s, and recreational abuse can be traced back many decades, rapid increase in use began in the mid-2000s, likely fueled by the legality of these substances. Mephedrone and MDPV have been the dominant synthetic cathinones of abuse in recent years, and are implicated in an increasing number of emergency department visits due to adverse effects. Case series and poison center data indicate that toxicity includes significant sympathomimetic effects, as well as psychosis, agitation, aggression, and sometimes violent and bizarre behavior. Multiple deaths attributed to synthetic cathinone use have been reported. There is a paucity of data concerning the pharmacodynamics and pharmacokinetics of synthetic cathinones in humans, with current understanding based primarily on in vitro and animal studies. Long-term effects of synthetic cathinone use, including the potential for addiction/dependence, are largely unknown. Although mephedrone and MVPV are now illegal in many countries, the current landscape of synthetic cathinone abuse will likely continue to shift as new substances are developed and marketed, and as legal pressures change.

\section{Disclosure}

The author reports no conflicts of interest in this work.

\section{References}

1. US Department of Justice National Drug Intelligence Center. Situation report: Synthetic cathinones (bath salts) - an emerging domestic threat. 2011. Available from: http://www.justice.gov/archive/ndic/ pubs44/44571/44571p.pdf. Accessed December 10, 2012.

2. Kalix P, Braenden O. Pharmacological aspects of the chewing of khat leaves. Pharmacol Rev. 1985;37(2):149-164.

3. [No authors listed]. Review of the pharmacology of khat. Report of a WHO advisory group. Bull Narc. 1980;32(3):83-93.

4. Szendrei K. The chemistry of khat. Bull Narc. 1980;32(3):5-35.

5. United Nations. Studies on the chemical composition of khat. III. Investigations on the phenylalkylamine fraction. UN document MNAR/11/1975.

6. Peterson DW, Maitai CK, Sparber SB. Relative potencies of two phenylalkylamines found in the abused plant Catha edulis, khat. Life Sci. 1980;27(22):2143-2147.

7. Berrang BD, Lewin AH, Carroll FI. Enantiomeric alphaaminopropiophenones (cathinone): preparation and investigation. J Org Chem. 1982;47(13):2643-2647.

8. Luqman W, Danowski TS. The use of khat (Catha edulis) in Yemen. Social and medical observations. Ann Intern Med. 1976;85(2):246-249.

9. Dargan PI, Albert S, Wood DM. Mephedrone use and associated adverse effects in school and college/university students before the UK legislation change. QJM. 2010;103(11):875-879.

10. Kelly JP. Cathinone derivatives: a review of their chemistry, pharmacology and toxicology. Drug Test Anal. 2011;3(7-8):439-453.

11. Glennon RA, Young R, Martin BR, Dal Cason TA. Methcathione ("cat"): an enantiomeric potency comparison. Pharmacol Biochem Behav. 1995;50(4):601-606.

12. Galvan-Arzate S, Santamaria A. Neurotoxicity of diethylpropion: neurochemical and behavioral findings in rats. Ann N Y Acad Sci. 2002;965:214-224.
13. Gardos G, Cole JO. Evaluation of pyrovalerone in chronically fatigued volunteers. Curr Ther Res Clin Exp. 1971;13(10):631-635.

14. Advisory Council on the Misuse of Drugs. ACMD report on the consideration of the cathinones. 2010. Available from: http://www.homeoffice. gov.uk/acmd1/acmd-cathinodes-report-2010?view=Binary. Accessed November 1, 2012.

15. Coppola M, Mondola R. Synthetic cathinones: chemistry, pharmacology and toxicology of a new class of designer drugs of abuse marketed as "bath salts" or "plant food." Toxicol Lett. 2012;211(2):144-149.

16. James D, Adams RD, Spears R, et al. Clinical characteristics of mephedrone toxicity reported to the UK National Poisons Information Service. Emerg Med J. 2011;28(8):686-689.

17. Thornton SL, Gerona RR, Tomaszewski CA. Psychosis from a bath salt product containing flephedrone and MDPV with serum, urine, and product quantification. $J$ Med Toxicol. 2012;8(3):310-313.

18. Centers for Disease Control and Prevention (CDC). Emergency department visits after use of a drug sold as "bath salts" - Michigan, November 13, 2010-March 31, 2011. MMWR Morb Mortal Wkly Rep. 2011;60(19): 624-627.

19. Spiller HA, Ryan ML, Weston RG, Jansen J. Clinical experience with and analytical confirmation of "bath salts" and "legal highs" (synthetic cathinones) in the United States. Clin Toxicol. 2011;49(6):499-505.

20. Dick D, Torrance C. Mixmag drugs survey. Mixmag. 2010;225: 44-53.

21. American Association of Poison Control Centers (AAPCC). Bath salts data. 2012. Available from: https://aapcc.s3.amazonaws.com/ files/library/Bath_Salts_Data_for_Website_1.09.2013.pdf. Accessed December 15, 2012

22. Drug Enforcement Administration. Special Report: Synthetic Cannabinoids and Synthetic Cathinones Reported in NFLIS, 2009-2010. Springfield (VA): DEA; 2011. Available from: http://www.deadiversion. usdoj.gov/nflis/2010rx_synth.pdf. Accessed December 10, 2012.

23. Dargan PI, Sedefov R, Gallegos A, Wood DM. The pharmacology and toxicology of the synthetic cathinone mephedrone (4-methylmethcathinone). Drug Test Anal. 2011;3(7-8):454-463.

24. Regan L, Mitchelson M, Macdonald C. Mephedrone toxicity in a Scottish emergency department. Emerg Med J. 2011;28(12): 1055-1058.

25. Drug Enforcement Administration. Schedules of controlled substances: placement of ezogabine into Schedule V. Final rule. Fed Regist. 2011;76(241):77895-77899.

26. Kalix P. Cathinone, a natural amphetamine. Pharmacol Toxicol. 1992; 70(2):77-86.

27. Toennes SW, Harder S, Schramm M, Niess C, Kauert GF. Pharmacokinetics of cathinone, cathine and norephedrine after the chewing of khat leaves. Br J Clin Pharmacol. 2003;56(1):125-130.

28. Widler P, Mathys K, Brenneisen R, Kalix P, Fisch HU. Pharmacodynamics and pharmacokinetics of khat: a controlled study. Clin Pharmacol Ther. 1994;55(5):556-562.

29. Brenneisen R, Fisch HU, Koelbing U, Geisshusler S, Kalix P. Amphetamine-like effects in humans of the khat alkaloid cathinone. Br J Clin Pharmacol. 1990;30(6):825-828.

30. Guantai AN, Maitai CK. Metabolism of cathinone to d-norpseudoephedrine in humans. J Pharm Sci. 1983;72(10):1217-1218.

31. Toennes SW, Kauert GF. Excretion and detection of cathinone, cathine, and phenylpropanolamine in urine after kath chewing. Clin Chem. 2002;48(10):1715-1719.

32. Kalix P. Pharmacological properties of the stimulant khat. Pharmacol Ther. 1990;48(3):397-416.

33. Meyer MR, Wilhelm J, Peters FT, Maurer HH. Beta-keto amphetamines: studies on the metabolism of the designer drug mephedrone and toxicological detection of mephedrone, butylone, and methylone in urine using gas chromatography-mass spectrometry. Anal Bioana Chem. 2010;397(3):1225-1233.

34. Zaitsu K, Katagi M, Kamata HT, et al. Determination of the metabolites of the new designer drugs bk-MBDB and bk-MDEA in human urine. Forensic Sci Int. 2009;188(1-3):131-139. 
35. Kamata HT, Shima N, Zaitsu K, et al. Metabolism of the recently encountered designer drug, methylone, in humans and rats. Xenobiotica. 2006;36(8):709-723.

36. Meyer MR, Du P, Schuster F, Maurer HH. Studies on the metabolism of the alpha-pyrrolidinophenone designer drug methylenedioxy-pyrovalerone (MDPV) in rat and human urine and human liver microsomes using GC-MS and LC-high-resolution MS and its detectability in urine by GC-MS. J Mass Spectrom. 2010;45(12):1426-1442.

37. Meyer MR, Vollmar C, Schwaninger AE, Wolf E, Maurer HH. New cathinone-derived designer drugs 3-bromomethcathinone and 3-fluoromethcathinone: studies on their metabolism in rat urine and human liver microsomes using GC-MS and LC-high-resolution MS and their detectability in urine. J Mass Spectrom. 2012;47(2):253-262.

38. Khreit OI, Grant MH, Zhang T, Henderson C, Watson DG, Sutcliffe OB. Elucidation of the phase I and phase II metabolic pathways of (+/-)-4'-methylmethcathinone (4-MMC) and (+/-)-4'-(trifluoromethyl) methcathinone (4-TFMMC) in rat liver hepatocytes using LC-MS and LC-MS(2). J Pharm Biomed Anal. 2013;72:177-185.

39. Pawlik E, Plässer G, Mahler H, Daldrup T. Studies on the phase I metabolism of the new designer drug 3-fluoromethcathinone using rabbit liver slices. Int J Legal Med. 2012;126(2):231-240.

40. Mueller DM, Rentsch KM. Generation of metabolites by an automated online metabolism method using human liver microsomes with subseAnal Bioanal Chem. 2012;402(6):2141-2151.

41. Psychonaut WebMapping Research Group. Mephedrone Report. London: Institute of Psychiatry, King's College London; 2009.

42. Newcombe R. Mephedrone: The Use of Mephedrone (M-cat, Meow) in Middlesbrough. Manchester: Lifeline Publications and Research; 2009.

43. Gibbons S, Zloh M. An analysis of the 'legal high' mephedrone. Bioorg Med Chem Lett. 2010;20(14):4135-4139.

44. Simmler LD, Buser TA, Donzelli M, et al. Pharmacological characterization of designer cathinones in vitro. Br J Pharmacol. 2013;168(2):458-470.

45. Cozzi NV, Sievert MK, Shulgin AT, Jacob P 3rd, Ruoho AE. Inhibition of plasma membrane monoamine transporters by beta-ketoamphetamines. Eur J Pharmacol. 1999;381(1):63-69.

46. Lopez-Arnau R, Martinez-Clemente J, Pubill D, Escubedo E, Camarasa J. Comparative neuropharmacology of three psychostimulant cathinone derivatives: butylone, mephedrone and methylone. Br J Pharmacol. 2012;167(2):407-420.

47. Wood DM, Greene SL, Dargan PI. Clinical pattern of toxicity associated with the novel synthetic cathinone mephedrone. Emerg Med J. 2011;28(4):280-282

48. Kehr J, Ichinose F, Yoshitake S, et al. Mephedrone, compared with MDMA (ecstasy) and amphetamine, rapidly increases both dopamine 2011;164(8):1949-1958.

49. Davies S, Wood DM, Smith G, et al. Purchasing 'legal highs' on the Internet - is there consistency in what you get? QJM. 2010;103(7): 489-493.

50. European Monitoring Centre for Drugs and Drug Addiction. Report on the Risk Assessment of Mephedrone in the framework of the Council Decision on New Psychoactive Substances. Lisbon: EMCDDA; 2011.

51. Sauer C, Hoffmann K, Schimmel U, Peters FT. Acute poisoning involving the pyrrolidinophenone-type designer drug 4'-methyl-alphapyrrolidinohexanophenone (MPHP). Forensic Sci Int. 2011;208(1-3): e20-e25. quent identification by LC-MS(n), and metabolism of 11 cathinones. and 5-HT levels in nucleus accumbens of awake rats. Br J Pharmacol.

52. Brunt TM, Poortman A, Niesink RJ, van den Brink W. Instability of the ecstasy market and a new kid on the block: mephedrone. J Psychopharmacol. 2011;25(11):1543-1547.

53. Al-Motarreb A, Briancon S, Al-Jaber N, et al. Khat chewing is a risk factor for acute myocardial infarction: a case-control study. $\mathrm{Br} \mathrm{J} \mathrm{Clin}$ Pharmacol. 2005;59(5):574-581.

54. Balint EE, Falkay G, Balint GA. Khat - a controversial plant. Wien Klin Wochenschr. 2009;121(19-20):604-614.

55. Forrester MB. Synthetic cathinone exposures reported to Texas poison centers. Am J Drug Alcohol Abuse. 2012;38(6):609-615.

56. Borek HA, Holstege CP. Hyperthermia and multiorgan failure after abuse of "bath salts" containing 3,4-methylenedioxypyrovalerone. Ann Emerg Medicine. 2012;60(1):103-105.

57. Sammler EM, Foley PL, Lauder GD, Wilson SJ, Goudie AR, O'Riordan JI. A harmless high? Lancet. 2010;376(9742):742.

58. Iqbal M, Monaghan T, Redmond J. Manganese toxicity with ephedrone abuse manifesting as parkinsonism: a case report. J Med Case Rep. 2012;6(1):52.

59. Yildirim EA, Eşsizoğlu A, Köksal A, Doğu B, Baybaş S, Gökalp P. [Chronic manganese intoxication due to methcathinone (ephedron) abuse: a case report]. Turk Psikiyatri Derg. 2009;20(3):294-298. Turkish.

60. Ellison G. Neural degeneration following chronic stimulant abuse reveals a weak link in brain, fasciculus retroflexus, implying the loss of forebrain control circuitry. Eur Neuropsychopharmacol. 2002; 12(4):287-297.

61. Puerta E, Hervias I, Aguirre N. On the mechanisms underlying 3,4-methylenedioxymethamphetamine toxicity: the dilemma of the chicken and the egg. Neuropsychobiology. 2009;60(3-4):119-129.

62. den Hollander B, Rozov S, Linden AM, Uusi-Oukari M, Ojanpera I, Korpi ER. Long-term cognitive and neurochemical effects of "bath salt" designer drugs methylone and mephedrone. Pharmacol Biochem Behav. 2012;103(3):501-509.

63. Mixmag. Mixmag's drug survey: the results. 2012. Available from: http://www.mixmag.net/drugssurvey. Accessed December 1, 2012.

64. Van Hout MC, Bingham T. "A costly turn on": patterns of use and perceived consequences of mephedrone based head shop products amongst Irish injectors. Int J Drug Policy. 2012;23(3):188-197.

65. Wood DM, Davies S, Greene SL, et al. Case series of individuals with analytically confirmed acute mephedrone toxicity. Clin Toxicol. 2010;48(9):924-927.

66. Pearson JM, Hargraves TL, Hair LS, et al. Three fatal intoxications due to methylone. J Anal Toxicol. 2012;36(6):444-451.

67. Adamowicz P, Tokarczyk B, Stanaszek R, Slopianka M. Fatal mephedrone intoxication - a case report. J Anal Toxicol. 2013;37(1):37-42.

68. Wood DM, Davies S, Puchnarewicz M, et al. Recreational use of mephedrone (4-methylmethcathinone, 4-MMC) with associated sympathomimetic toxicity. J Med Toxicol. 2010;6(3):327-330.

69. Murray BL, Murphy CM, Beuhler MC. Death following recreational use of designer drug "bath salts" containing 3,4-methylenedioxypyrovalerone (MDPV). J Med Toxicol. 2012;8(1):69-75.

70. Derungs A, Schietzel S, MeyerMR, MaurerHH, Krahenbuhl S, LiechtiME. Sympathomimetic toxicity in a case of analytically confirmed recreational use of naphyrone (naphthylpyrovalerone). Clin Toxicol. 2011;49(7):691-693.

Clinical Pharmacology: Advances and Applications

\section{Publish your work in this journal}

Clinical Pharmacology: Advances and Applications is an international, peer-reviewed, open access journal publishing original research, reports, reviews and commentaries on all areas of drug experience in humans. The manuscript management system is completely online and includes a very quick and fair peer-review system, which is all easy to use.

\section{Dovepress}

Visit http://www.dovepress.com/testimonials.php to read real quotes from published authors. 